\title{
Electrophysiological study on limb myokymia in three
}

\section{women}

\author{
SHINICHI HOSOKAWA, HISAHARU SHINODA, TETSUO SAKAI,* \\ MOTOHIRO KATO, YOSHIGORO KUROIWA
}

From the Departments of Neurophysiology and Neurology, Neurological Institute, Faculty of Medicine, Kyushu University, Fukuoka, Japan

SUMMARY Physiological studies on three women with limb myokymia were carried out. The patients had diabetic neuropathy, neuromyotonia, and autonomic polyneuropathy, respectively. The EMG discharge pattern, coincident with myokymia, in a patient with myokymia and neuromyotonia differed from those with myokymia without neuromyotonia. In only the first patient did the electrical stimulation of nerves evoke "late repetitive response" (LRR), which resembled the wave forms of the myokymic discharge. Epidural and peripheral nerve blocks abolished myokymia in the first and second cases, but peripheral nerve block was without effect in the third patient. These findings indicate that myokymia originates in multiple sites of alpha motor neurons and that the pathophysiology may vary.

The term "myokymia" is used clinically to describe involuntary contraction of muscle which is undulating, vermicular and wave-like. ${ }^{1}$ Facial myokymia is the most common type and is frequently associated with multiple sclerosis or brain stem neoplasms. Limb myokymia, which is relatively rare, seems to be associated with radiation-induced plexopathy, ${ }^{2}$ neuromyotonia, ${ }^{3-7}$ and other varieties of diseases including lead poisoning, ${ }^{8}$ thyrotoxicosis, ${ }^{9}$ chronic recurrent polyneuropathy, ${ }^{10}$ and peripheral nerve injury. ${ }^{11}$

Typical myokymic discharges are composed of spontaneous, semi-rhythmic bursts of motor unit potentials. However, other types of discharge have been included in cases of myokymia in many reports. $^{23712-14}$ There is debate concerning the origin and pathophysiological mechanism of myokymia. ${ }^{27101415}$ Most reports were of a single case, ${ }^{367131416}$ or several cases with the same electromyographic findings. ${ }^{2}$ We studied limb myokymia in three Japanese women with variations in the clini-

\footnotetext{
*Present address: Department of Neurology, National Chikugo Hospital, 515 Kurakazu, Chikugo-city, Fukuoka 833, Japan
}

Address for reprint requests: Shinichi Hosokawa, M.D., Department of Neurophysiology, Neurological Institute, Faculty of Medicine, Kyushu University 60, Higashi-ku, Fukuoka 812, Japan.

Received 8 April 1986 and in revised form 16 November 1986. Accepted 22 November 1986 cal picture, using the same electrophysiological procedures in an attempt to clarify the underlying mechanism of limb myokymia.

\section{Case reports}

\section{Clinical data}

A summary of clinical data on the three women is given in table 1. Clinical details of case 2 have been previously reported. ${ }^{17}$ All three women had limb myokymia consisting of continuous, undulating, worm-like, irregular, asynchronous and slow muscular contractions. The distribution of myokymia was in bilateral quadriceps and gastrocnemius muscles in case 1 , and was in the bilateral calf muscles in case 3 . In case 2 , the mixed muscular twitchings of fasciculation, which was rather brisk and sporadic, and myokymia, which was a continuous, slow and undulating contraction were observed in the bilateral masseters, forearm, quadriceps, and gastrocnemius muscles. The limb myokymia persisted during sleep and was not affected by cooling or warming the skin. None of the three women had muscular weakness or atrophy.

In case 1 , the clinical picture and findings of sural nerve biopsy were consistent with diabetic neuropathy. Only case 2 had characteristic features of neuromyotonia, such as delayed muscular relaxation after contraction, muscular habitus, myokymia, fasciculation, and lack of percussion myotonia. The third patient had a chronic autonomic predominant polyneuropathy with orthostatic hypotension, an atonic bladder and hypohidrosis. The underlying disease could not be elucidated, although amyloidosis and diabetic neuropathy were ruled out by laboratory findings, including rectal and sural nerve biopsies. 
Table 1 Summary of clinical data*

\begin{tabular}{|c|c|c|c|}
\hline & Case 1 & Case 2 & Case 3 \\
\hline $\begin{array}{l}\text { Age (yr) } \\
\text { Age at onset (yr) } \\
\text { Heredity } \\
\text { Past history }\end{array}$ & $\begin{array}{l}66 \\
64 \\
\text { 1. partial thyroidectomy } \\
\text { 2. diabetes mellitus }\end{array}$ & $\frac{23}{17}$ & $\begin{array}{l}70 \\
66 \\
\frac{1}{n . c} .\end{array}$ \\
\hline Signs & $\begin{array}{l}\text { 1. limb myokymia } \\
\text { 2. DTR } \downarrow \\
\text { 3. sensation } \downarrow\end{array}$ & $\begin{array}{l}\text { 1. limb myokymia } \\
\text { 2. fasciculation } \\
\text { 3. excessive sweating } \\
\text { 4. muscular relaxation } \downarrow \\
\text { 5. muscular hypertrophy } \\
\text { 6. DTR } \downarrow\end{array}$ & $\begin{array}{l}\text { 1. limb myokymia } \\
\text { 2. sweating } \downarrow \\
\text { 3. orthostatic hypotension } \\
\text { 4. dysuria } \\
\text { 5. DTR } \downarrow \\
\text { 6. emaciation }\end{array}$ \\
\hline Laboratory findings & $\begin{array}{l}\text { 1. diabetes mellitus } \\
\text { 2. sural nerve biopsy: abnormal } \\
\text { 3. muscle biopsy: neuropathic }\end{array}$ & $\begin{array}{l}\text { 1. } \underset{\mathrm{BMR} \uparrow}{\text { 2. }} \uparrow \uparrow \\
\mathrm{CK} \uparrow\end{array}$ & $\begin{array}{l}\text { 1. hypoalbuminemia } \\
\text { 2. atonic bladder } \\
\text { 3. ECG R-R interval: abnormal }\end{array}$ \\
\hline
\end{tabular}

*Key to abbreviations: - , absent; $\downarrow$, decreased; $\uparrow$, increased; n.c., not contributory; DTR, deep tendon reflexes; BMR, basal metabolic rate; CK, creatine kinase.

Electrophysiological study

Needle EMG In case of conventional needle EMG, there were abnormal spontaneous discharges at rest in all three women (fig 1). In case 1, the bursts of motor unit potentials (MUP) appeared at irregular intervals (1-3 bursts per second), with a duration of $60-100 \mathrm{~ms}$ and the amplitude of $200-1000 \mu \mathrm{V}$, coincident with myokymia. In case 2 , the pat- tern was composed of continuous appearances of single or multiple motor unit potentials at the high frequency of $30-50 \mathrm{~Hz}$. It was impossible to recognise a coincident EMG discharge together with a visible myokymia and fasciculation. In case 3, there were intermittent arrhythmic appearances of multiple or single motor unit potentials with an average frequency of $3-10 \mathrm{~Hz}$. In all three, there was no
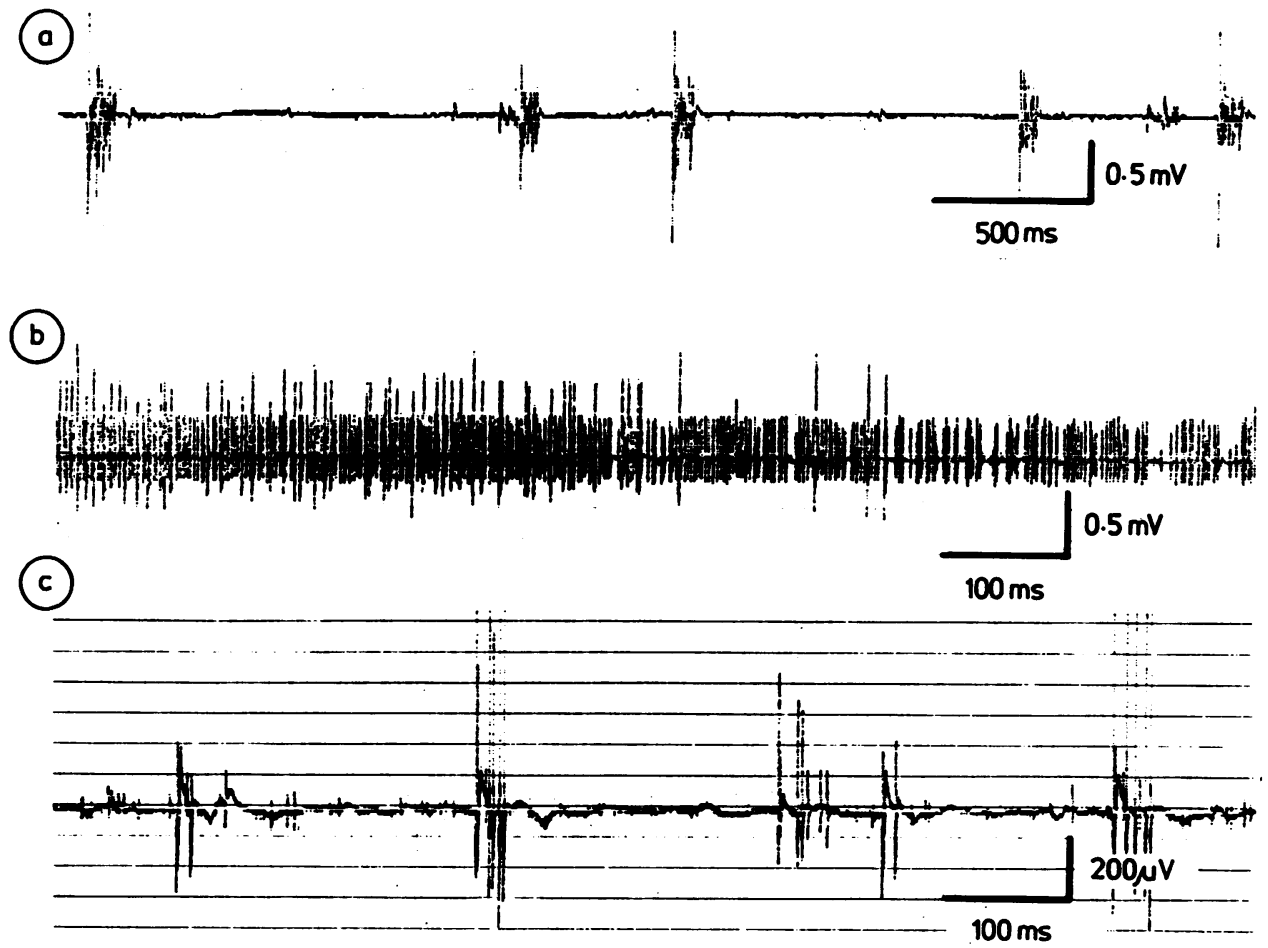

Fig 1 The spontaneous EMG discharge at rest, coincident with myokymia, in the right gastrocnemius muscle. In case $I(a)$, the bursts of motor unit potentials (MUP), with duration of 60-100 ms and amplitude of 200-1000 $\mu \mathrm{V}$, appear with irregular intervals (1-3 bursts per second). Case 2 (b) shows the continuous appearance of MUP at a high frequency of $30-50 \mathrm{~Hz}$. Case 3 (c) shows intermittent appearance of multiple $M U P$, at a frequency of $3-10 \mathrm{~Hz}$. 
denervation potential, myotonic discharge, or abnormality in MUP during weak contraction.

Evoked EMG Motor (MCV), sensory (SCV), and F wave conduction velocity (FWCV) were measured using standard techniques and surface electrodes ${ }^{8}$ and the results are shown in table 2 . In case 1 , there was a mild impairment of $\mathrm{MCV}$ and FWCV of the tibial nerve and nerve action potential could not be evoked at the sural nerve. In case $2, \mathrm{MCV}$ was mildly impaired in the tibial and ulnar nerves and FWCV was impaired in the tibial nerve. In case 3 , there was mild impairment of FWCV in the tibial nerve. The $\mathrm{H}$-reflex was absent or of low amplitude in the gastrocnemium muscle, in these three women.

In only case 1 did electrical stimulation of the tibial, peroneal and median nerves evoke "late repetitive response" (LRR), which has the constant latency from the stimulation. The LRR could be evoked in the proximal as well as the distal muscles. The latency of LRR was $48 \mathrm{~ms}$ in the abductor hallucis muscle when the tibial nerve was stimulated at the medial malleolus, and $\mathbf{4 0} \mathrm{ms}$ when stimulated at the popliteal fossa (fig 2). The threshold of LRR was as low as the $M$ response and could be evoked even by supramaximal stimulation. The duration of LRR was about $60-70 \mathrm{~ms}$ and the LRR resembled the wave forms of the spontaneous myokymic discharge when recorded using conventional concentric needle electrodes (fig 3). The recovery curve of LRR by paired stimulation demonstrated a refractory period between 100 and $300 \mathrm{~ms}$. The duration of LRR by the test stimulus was longer than that by the conditioning stimulus, at intervals of 500 and $600 \mathrm{~ms}$. Thus, the total amount of EMG activity in LRR by the test stimulus was increased at these intervals (fig 4).

\section{Effect of nerve block}

Epidural block with $5 \mathrm{ml}$ of $0.3 \%$ carbocaine abolished the spontaneous myokymic discharges and LRR in case 1 , even when the $M$ response remained unchanged. Epidural block with $11.5 \mathrm{ml}$ of $2 \%$ carbocaine markedly but incompletely paralysed the quadriceps femoris muscle, with a substantial reduction in spontaneous myokymic discharges in case 2. Tibial nerve block at the ankle abolished both myokymic discharges and the $M$ response at the periphery distal to the block, in cases 1 and 2 . In the third, the myokymic discharges remained unchanged with peripheral nerve block, even when the $M$ response was abolished.

\section{Effect of drugs}

Diphenylhydantoin and carbamazepine were markedly effective for treating the myokymia in these three women. Dantrolene sodium was also markedly effective for case 2

Table 2 Nerve conduction velocities in three women

\begin{tabular}{|c|c|c|c|}
\hline & Case 1 & Case 2 & Case 3 \\
\hline $\begin{array}{l}\text { MCV } \\
\text { Rt. tibial } \\
\text { Rt. ulnar }\end{array}$ & $\begin{array}{l}40 \\
50\end{array}$ & $\begin{array}{l}39 \\
46\end{array}$ & $\begin{array}{l}44(n>41) \\
54(n>47)\end{array}$ \\
\hline $\begin{array}{l}\text { SCV } \\
\text { Rt. sural } \\
\text { FWCV }\end{array}$ & ne & 39 & $38(n>37)$ \\
\hline $\begin{array}{l}\text { Rt. tibial } \\
\text { H reflex }\end{array}$ & $\begin{array}{l}44 \\
\text { ne }\end{array}$ & $\begin{array}{l}46 \\
\text { low }\end{array}$ & $\begin{array}{l}45(n>49) \\
n e\end{array}$ \\
\hline
\end{tabular}

ne, not evoked.

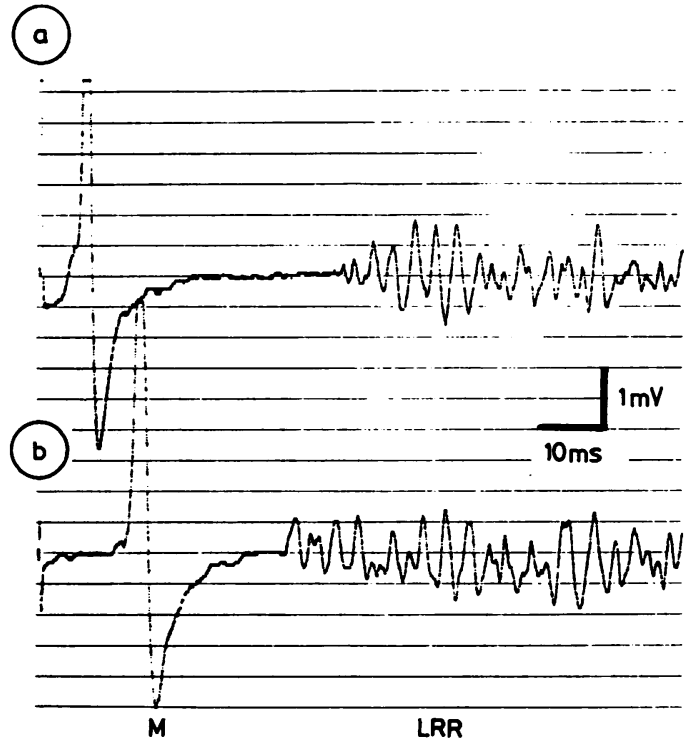

Fig 2 Responses recorded from the abductor hallucis muscle with a surface electrode, in response to stimulation of the tibial nerve at the medial malleolus (a) and the popliteal fossa (b) in case $1 . M$ : M response, LRR: late repetitive response.

and diazepam was without effect for treating the myokymia, in any patient.

\section{Discussion}

In all three women there was limb myokymia which was continuous, undulating, worm-like, irregular, asynchronous with slow muscle contractions. However, the remaining clinical picture differed among three patients. In case 1 , myokymia was accompanied by polyneuropathy, consistent with diabetic neuropathy. In case 2, there were characteristic features of neuromyotonia: ${ }^{18}$ delayed relaxation after contraction, muscular habitus, myokymia, fasciculation, and lack of percussion myotonia. The third patient had a chronic predominant autonomic polyneuropathy.

Electromyographic discharges coincident with myokymia differed between the woman with neuromyotonia and those without neuromyotonia, as previously reported, ${ }^{2-47813}$ That is, in case 2 with neuromyotonia, there was a single or multiple motor unit potential at a high frequency of $30-50 \mathrm{~Hz}$. On the other hand, in cases 1 and 3 , without neuromyotonia, the myokymic discharges were essentially composed of an arrhythmic appearance of bursts of motor unit potentials.

Another common feature of these three patients was mild polyneuropathy, as revealed by a delayed 


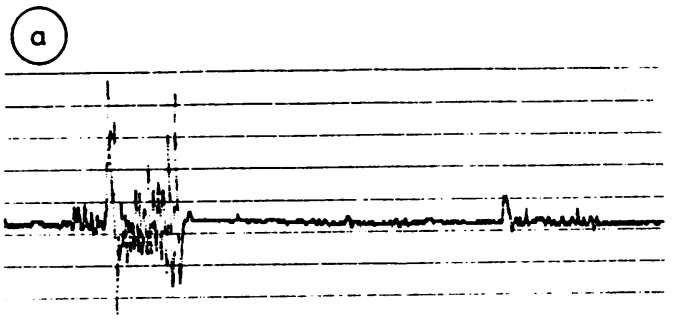

(b)

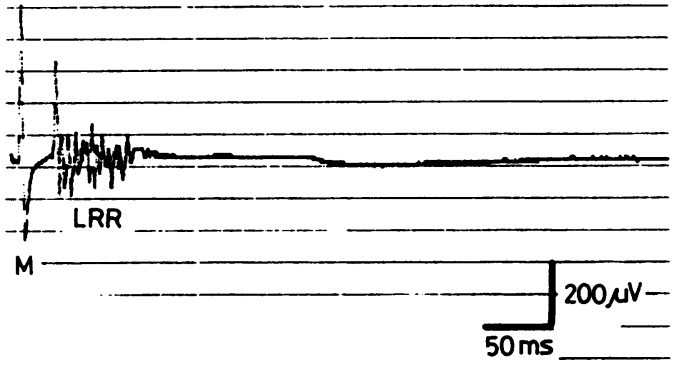

Fig 3 The spontaneous myokymic discharge (a) and evoked $M$ response $(M)$ and "late repetitive response' $(L R R)(b)$ in the gastrocnemius muscle in case 1 , recorded using the conventional concentric needle electrode.

nerve conduction velocity. Myokymia has been noted in conditions which affect the peripheral nerves. ${ }^{2710-12}$ Although the polyneuropathy may be secondary to the continuous appearance of myokymia, it may also be relevant to the pathogenesis of myokymia. ${ }^{2710}$

The effect of nerve block in these three patients indicated that the myokymia may have originated from multiple sites on the alpha motor neurons. ${ }^{2}$ The lumbar epidural and peripheral nerve blocks abolished myokymia in cases 1 and 2; therefore, myokymia in these patients probably arose from the anterior horn cell or ventral root. Myokymia in case 3 may have originated in the distal area of the peripheral nerve ${ }^{2}$ since it persisted even after the peripheral nerve block.

Late repetitive response (LRR), observed only in case 1 , has only rarely been reported, ${ }^{1920}$ although similar repetitive afterdischarges following nerve stimulation have been found to occur after the $M$ response ${ }^{1216}$ and H-reflex. ${ }^{12}$ The LRR is similar to the F-wave, in the following respects: the threshold of the LRR was as low as the M response, LRR could be evoked even by supramaximal nerve stimulation, the latency of LRR was similar to the F-wave, and LRR was also observed in the distal muscles as well as in the gastrocnemius muscle. However, the morphology of LRR with an abnormally long duration and a concomitant disappearance of myokymic discharge and LRR by epidural block strongly suggests that the LRR and myokymic discharge are closely related. The latency of LRR would be at an appropriate time for

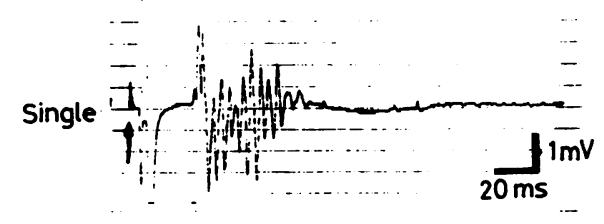

500

80

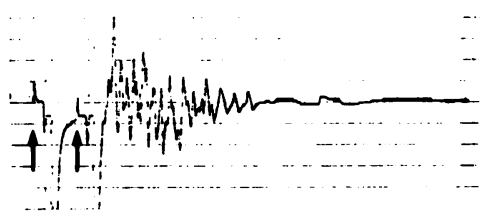

100

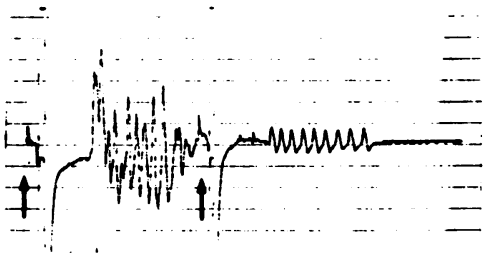

300
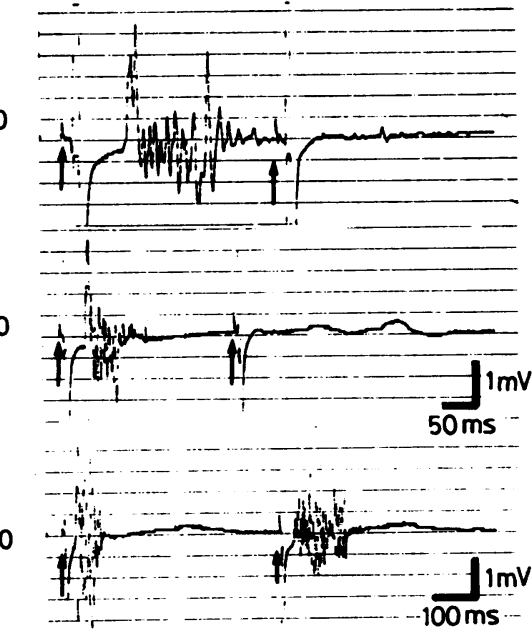

600

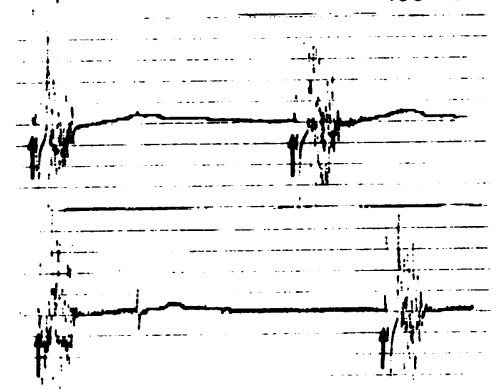

Fig 4 The "late repetitive response" ( $L R R)$ in the gastrocnemius by paired stimulation of the tibial nerve in case 1 . The numbers on the left indicate the time interval (ms) between conditioning and test stimuli, and the arrows the time of stimuli. The LRR has the refractory period between $100-300 \mathrm{~ms}$, and the hyperexcitability between 500 and $600 \mathrm{~ms}$ since the total amount of EMG activity in LRR by the test stimulus was increased at these intervals. Note the difference in time scale as indicated on the right. 
an antidromic impulse in the motor fibres to reach the anterior horn cell and for the repetitive discharge to return to the muscle. This also suggests that the myokymia and LRR may arise in the anterior horn cell or ventral root. The recovery curve of LRR by paired stimulation showed a long refractory period of LRR between $100-300 \mathrm{~ms}$, and the hyperexcitability at intervals of 500 and $600 \mathrm{~ms}$ was suggested since the total amount of EMG activity in LRR by test stimulus was increased at these intervals. The long refractory period cannot be explained by the refractory period of the peripheral nerve. Therefore, changes in the excitability of the anterior horn cells may play a role in the genesis of LRR. It is possible that the change in excitability of the anterior horn cell may be caused either by dysfunction of the anterior horn cell itself or by dysfunction of the interneurons to the anterior horn cell within the spinal cord. Another possibility is that the abnormal hyperexcitability of the anterior horn cell may be caused by chronic influx of abnormal impulses arising at the peripheral lesion ${ }^{20}$ due to diabetic neuropathy. It is noteworthy that a similar LRR has been noted in a patient with neuromyotonia and a mediastinal malignancy. ${ }^{21}$ Thus, there may be a common mechanism in the genesis of myokymia between patients with neuromyotonia and those without neuromyotonia.

In conclusion, the limb myokymia in our patients probably originated in multiple sites of the alpha motor neuron, the proximal area of the motor neuron in two and the distal region in one. Change in the excitability of the anterior horn cell was probable in one patient. Since the electromyographic pattern in case of myokymia and neuromyotonia differed from patterns of myokymia without neuromyotonia, these events should probably be considered to be in separate categories. Nevertheless, a common pathophysiological mechanism may exist, as determined by the effect of nerve block and the appearance of abnormally evoked repetitive responses.

We thank M Ohara (Kyushu University) for comments on the manuscript.

\section{References}

1 Schultze P. Beitrage Zur muskelpathologie. Dtsch $Z$. Nervenheilkd 1985;6:65-70.

2 Albers JW, Allen AA, Bastron JA, Daube JR. Limb myokymia. Muscle Nerve 1981;4:494-504.

3 Hughes RC, Matthews WB. Pseudo-myotonia and myo- kymia. J Neurol Neurosurg Psychiatry 1969;32:11-4.

4 Isaacs $H$. A syndrome of continuous muscle-fibre activity. J Neurol Neurosurg Psychiatry 1961;24:319-25.

5 Jackson DL, Satya-Murti S, Davis L, Drachman DB. Isaacs syndrome with laryngeal involvement: an unusual presentation of myokymia. Neurology 1979; 29:1612-5.

6 Sarova-Pinchas I, Goldhammer Y, Braham J. Multifocal myokymia. Muscle Nerve 1978;1:253-4.

7 Wallis WE, Van Poznak A, Plum F. Generalized muscular stiffness, fasciculations, and myokymia of peripheral nerve origin. Arch Neurol 1970;22:430-9.

$8 \mathrm{Kimura} \mathrm{J}$. Electrodiagnosis in Diseases of Nerve and Muscle: Principle and Practice. Philadelphia: FA Davis Co, 1983:554-5.

9 Harman JB, Richardson AT. Generalized myokymia and thyrotoxicosis. Lancet 1954;ii:473.

10 Valenstein E, Watson RT, Parker JL. Myokymia, muscle hypertrophy and percussion "myotonia" in chronic recurrent polyneuropathy. Neurology 1978;28:1130-4.

11 Medina JL, Chokroverty S, Reyes M. Localized myokymia caused by peripheral nerve injury. Arch Neurol 1976;33:587-8.

12 Auger RG, Daube JR, Gomez MR, Lambert EH. Hereditary form of sustained muscle activity of peripheral nerve origin causing generalized myokymia and muscle stiffness. Ann Neurol 1984;15:13-21.

13 Gardner-Medwin D, Walton JN. Myokymia with impaired muscular relaxation. Lancet 1969;1:127-30.

14 De Jong HH, Matzner IA, Unger AA. Clinical and physiological studies in a case of myokymia. Arch Neurol Psychiat 1951;65:181-8.

15 Greenhouse AH, Bicknell JM, Pesch RN, Seelinger DF. Myotonia, myokymia, hyperhidrosis, and wasting of muscle. Neurology 1967;17:263-8.

16 Walmolts JR, Mendell JR. Neurotonia: impulse-induced repetitive discharges in motor nerves in peripheral neuropathy. Ann Neurol 1980;7:245-50.

17 Sakai T, Hosokawa S, Shibasaki H, Goto I, Kuroiwa Y, Sonoda H, Murai Y. Syndrome of continuous musclefiber activity: increased CSF GABA and effect of dantrolene. Neurology 1983;33:495-8.

18 Mertens HG, Zschocke S. Neuromyotonie. Klin Wschr 1965;43:917-25.

19 Harayama H, Shirakawa K, Yuasa T, Fukuhara N, Tsubaki T. Clinical and electrophysiological studies on a case of myokymia. Evidence suggesting the hyperexcitability of the proximal alpha motor fibers. Clin Neurol (Tokyo) 1980;20:346-53.

20 Moller AR, Jannetta PJ. Hemifacial spasm: results of electrophysiologic recording during microvascular decompression operations. Neurology 1985;35:969-74.

21 Walsh JC. Neuromyotonia: an unusual presentation of intrathoracic malignancy. $J$ Neurol Neurosurg Psychiatry 1976;39:1086-91. 